\title{
Creative minds and neurosciences...
}

\section{Mentes creativas y neurociencias...}

\author{
Ricardo F. Allegri ${ }^{1}$
}

How to cite this article:

Allegri, R. F. (2021). Creative minds and neurosciences... Journal of Applied Cognitive Neuroscience, 2(1), e00173806.

https://doi.org/10.17981/JACN.2.1.2021.06

Manuscript received on 9th April 2021 Accepted on 12th June 2021

\begin{abstract}
Creativity is the ability to generate original ideas in the arts or sciences, leaving traditional stereotypes behind, ultimately introducing innovation to the social context in which they arise. It has been associated with "divergent thinking" which prioritizes the generation of multiple solutions, different from traditional ones. Some authors have observed creative individuals present higher incidence of affective disorders, possibly related to hypomania or disinhibition. Similarly, "creativity" has been described in patients with frontotemporal dementia, a brain region linked with creativity on fMRI. Creativity is one of the most salient characteristics that human beings possess

Keywords: Creativity; intelligence; divergent thinking; psychiatry; neurology; anatomy

Resumen

Creatividad es la habilidad de generar ideas originales en arte o ciencia, dejando atrás los estereotipos y produciendo innovaciones en el contexto social en el cual ocurren. Creatividad es asociada con pensamiento divergente que prioriza la generación de múltiples soluciones diferentes a las tradicionales. Algunos autores refirieron que era muy frecuente los trastornos afectivos en los pacientes creativos, esto probablemente mas relacionado a la hipomanía o la desinhibición como también ocurre en la demencia fronto-temporal. Estas regiones cerebrales fueron descriptas en los trabajos con resonancia funcional. La creatividad es una de las características mas relevantes que posee el ser humano.
\end{abstract}

Palabras clave: Creatividad; inteligencia; pensamiento divergente; psiquiatría; neurología; anatomía 


\section{INTRODUCCIÓN}

What was happening in Jorge Luis Borges' brain while he was writing "The Library of Babel", or in Rafael Nadal's when he won at Roland Garros? In what way were Albert Einstein and Pablo Picasso's brains different?

Creativity is one of the most important characteristics that human beings possess (Andreasen \& Ramchandran, 2012). One of the greatest challenges is defining the term "creativity". At the beginning of the 20th-century, creative people were considered geniuses, Howard Gardner described multiple types of creativity and referred to this as "multiple intelligence" Today the term refers more to individuals who make creative contributions.

There were three-stages in the history of theories on creativity (Sun-Hyung, Kwang Ki \& Jarang, 2016):

1. The first was the He-paradigm, that of the "lonely genius", the classical view of creativity, a great man like Leonardo Da Vinci for example, who produced an outstanding body of creative work (H-creativity or big $\mathrm{C}$ ).

2. The second stage was the I-paradigm based on individual creativity. This position considers all individuals can develop creativity (P-creativity, personal creativity, or little c).

3. The last stage was the We-paradigm, which argues that culture and cognition are correlated, and creativity is a cognitive process influenced by social context.

Simonton (2012) describes a continuum between "big C" (only a few individual geniuses) and "little c" (ordinary creativity which all people possess).

Currently, creativity is considered the ability to generate new and original ideas, leaving traditional stereotypes and patterns behind, introducing innovations into the social context in which these ideas arise. We live in a changing and increasingly complex world, in which creativity implies a reaction to the difficulties and challenges of the future; this innovative, transformative, and constructive capacity represents one of the engines of humanity's scientific and cultural evolution (Sun-Hyung et al., 2016). Art is but one example where humans demonstrate the capacity for creativity, but it would be a fallacy to believe that creativity is a characteristic unique to the artistic world. Today, creativity includes the arts (painting, literature, poetry, music, etc.) and sciences (mathematics, physics, chemistry, biology, etc.) (Zaidel, 2014). When brain activations are compared, findings give no support to the idea that artists and scientists represent two separate cultures. Both respond in similar ways, showing activation of brain circuits involved in higher-order socio-affective processing, and in REST (Random Episodic Silent Thought)/ the default mode network (resting-state on Brain MRI) (Andreasen \& Ramachandran, 2012).

The essential personality trait of a creative mind is "openness to new experience," which is translated into a particular interest in varied experimentation, which some call "intellectual curiosity". We should not equate creativity with intelligence. They can occur together, but also separately. In the case of intelligence, "convergent thinking" is prioritized to find the only, or if not that, at least an adequate solution to a problem. Creativity on the other hand is associated with "divergent thinking" which 
prioritizes the generation of many response possibilities, different starting points, and multiple solutions, different from traditional ones. Ordinary creativity can be stimulated and can develop in many people throughout their lifetime. Extraordinary creativity however, is innate, genetic, and only be seen in geniuses like Leonardo Da Vinci.

In the $18^{\text {th }}$ century, Lombroso (1881) postulated the source of genius was a constitutional defect related to insanity, whereas others thought it represented the greatest capacity of the human race (Galton, 1869). A more modern approach to the concepts of geniality and insanity, has been to replace the terms with creativity and mental illness (Hare, 1987). Some studies indicate creative individuals present higher incidence of affective disorders, and that geniuses tend to be introverts, in whose families there can be relatives with schizophrenia (Newton, Einstein, and Russel) (Hare, 1987). Under these circumstances, the discovery of an original and different solution can be mistaken for the extravagance of a delusion. Vincent Van Gogh for example, who suffered throughout his life from a severe mood disorder, produced more than 300 of his greatest works during periods of psychotic mania. Other famous and creative individuals exhibiting mood disorders include: Ernest Hemingway, Winston Churchill, and Theodore Roosevelt (Andreasen, 2008). Many writers seeking to trigger the effects of creativity while working (and some artists too, but few scientists it seems), have resorted to using drugs during the creative process (Hare, 1987). Alcohol has been the one chosen most often, but absinthe (Hemphill, 1961), or even cocaine have been other options, to name a few (Thornton, 1986). In these situations, disinhibition, or loss of impulse control is often mistaken for creativity. The study of the relationship between creativity and mental illnesses remains a relatively open territory, with much work still to be done to further the field (Andreasen, 2008).

What do we know about creativity in neurological and psychiatric diseases? Our brains are made up of circuits responsible for our behaviours. Nevertheless, they are still always the same circuits in the same brain. Zaidel (2014) for example speculated that in the healthy brain, cognitive associative networks in the left or right hemisphere (working alone or together), can contribute to the creative process in art. Other authors working with fMRI found greater participation of the left hemisphere in creativity (Gonnen-Yaacovi et al, 2013). Patients with lesions (e.g., tumours) in the temporal lobes, exhibit disinhibition and increased creativity, whereas those with frontal lesions present apathy, rigidity and inflexibility as well as decreased creativity. Functional neuroimaging data from healthy subjects shows the prefrontal cortex plays an important role in cognitive processes involved in creativity (Gonen-Yaacovi et al., 2013). In drawings made by patients with Alzheimer's dementia, decreased ability to appreciate details is observed as well as a tendency to disorganized disposition, a preference for darker tones, and a more significant distortion of faces (Serrano, Allegri, Martelli, Taragano \& Ranalli, 2005). In patients with frontotemporal dementia (Pick's disease), inhibitory controls are lost, and increased creativity can be seen (Serrano y Allegri, 2005; de Souza et al., 2014). Belief that psychiatric patients have high creative potential is quite widespread. Eysenck has suggested that creativity is related to psychoticism and 
that both underlie a cognitive style that can be identified as over-inclusiveness, which is closely related to divergent thinking. Over-inclusiveness may be due to a failure of inhibition present in psychotics and necessary in creatives. However, one must be prudent and not fall into false generalizations. This theory does not describe a direct association, it simply details common brain mechanisms that ultimately share neural circuits.

Where is creativity generated within our brains? Sperry's experiments in 1961 showed that the left and right hemispheres were functionally different. The right hemisphere was described as creative, operating in a holistic and globalizing fashion, and the left as logical, analytical, and rational. The error in this concept was to think only of artistic creativity for which the right hemisphere is responsible, anf forget about scientific creativity which is handled by the left hemisphere. Authors such as Flaherty in 2005 have proposed creative ideas are generated through an interaction between frontal and temporal lobes and the limbic system. In this hypothesis, neurotransmitters such as dopamine facilitate voluntary and single-goal-oriented activities while inhibiting competitive behaviours, striking a balance between frontal cortex-based rationality and temporallimbic cortex-based emotions.

Results from functional brain MRI studies showed divergent thinking correlated with well distributed bilateral brain activation in the left prefrontal cortex and the right medial temporal lobe, with deactivation of the right temporoparietal junction. Whereas when retrieval of old ideas was compared to generation of new ideas, increased activation was observed in the inferior parietal cortex of the left hemisphere (Benedek et al., 2014; SunHyung et al., 2016).

Is the brain of a genius different from that of a normal individual? Einstein's brain, one of the most studied in history, was significant in the search for brain characteristics indicative of genius and creativity. Einstein did think uniquely even though his brain weighed only 1230 grams, significantly less than the average in adults which is around 1400 grams. For many years, this was taken as evidence to support the paradigm of a lack of relationship between brain structure and function. It was only in 1999, that a study was published in which researchers found that the region responsible for mathematical thinking and visual-spatial skills was 15\% larger in Einstein's brain compared to others. Even if this was probably the source of Einstein's greater logical-mathematical ability, we still do not know where in his mind his creativity was harboured.

\section{Conclusions}

Jorge Luis Borges, Rafael Nadal, Albert Einstein, and Pablo Picasso all share the unique quality of the human genius, namely creativity in the highest degree together with the underlying brain processes that determine it. Creative minds are the ones pushing the evolution of the arts and science forward in societies, and ultimately the development of the human being. 


\section{REFERENCES}

Andreasen, N \& Ramchandran K. (2012). Creativity in art and science: are there two cultures? Dialogues in Clinical Neurosciences, 14(1), 49-54.

https://dx.doi.org/10.31887\%2FDCNS.2012.14.1\%2Fnandreasen

Andreasen, N. (2008). The relation between creativity and mood disorders. Dialogues in Clinical Neurosciences, 10(2), 251-255.

https://dx.doi.org/10.31887\%2FDCNS.2008.10.2\%2Fncandreasen

Benedek, M.; Jauk, E.; Fink, A.; Koschutnig, K.; Reishofer, G.; Ebner, F. \& Neubauer, A. (2014). To create or to recall? Neural mechanisms underlying the generation of creative new ideas. Neuroimage, 88, 125-133.

https://doi.org/10.1016/J.NEUROIMAGE.2013.11.021

De Souza, L. C.; Guimaraes, H. C.; Texeira, A. L.; Caracmelli, P.; Levy, R.; Dubois, B. \& Volle, E. (2014). Frontal lobe Neurology and the creative mind. Frontiers in Psychology, 5, 1-9.

https://doi.org/10.3389/fpsyg.2014.00761

Galton, F. (1869). Hereditary genius: an inquiry into its laws and consequences. London: McMillan.

Gonen-Yaacovi, G.; de Souza, L. C.; Levy, R.; Urbanski, M.; Josse, G. \& Volle, E. (2013). Rostral and caudal prefrontal contribution to creativity: a meta-analysis of functional imaging data. Frontiers in Human Neuroscience, 7, 1-22.

https://dx.doi.org/10.3389\%2Ffnhum.2013.00465

Hare, E. (1987). Creativity and mental illness. British Medical Journal (Clinical research ed.), 295(6613), 1587-1589.

https://dx.doi.org/10.1136\%2Fbmj.295.6613.1587

Hemphill, R. E. (1961). The illness of Vincent Van Gogh. Proceedings of the Royal Society of Medicine, 54(12), 1083-1088.

https://doi.org/10.1177\%2F003591576105401206

Lombroso C. (1981). The man of genius. London: Walter Scott.

Serrano. C.; Allegri, R.; Martelli, M.; Taragano. F. \& Ranalli, P. (2005). Visual Art, Creativity and Dementia. Vertex, 16(64), 418-429. Disponible en http://www.polemos.com.ar/vertex64.php

Serrano, C. M. y Allegri, R. F. (2005). Demencia Frontotemporal: un nuevo enfoque a través del arte. Revista Neurológica Argentina, 30(1), 43-50.

Simonton, D. K. (2012). Quantifying creativity: can measures span the spectrum? Dialogues in clinical neuroscience, 14(1), 100-104.

https://dx.doi.org/10.31887\%2FDCNS.2012.14.1\%2Fdsimonton

Sun-Hyung, P.; Kwang Ki, K. \& Jarang, H. (2016). Neuro-Scientific Studies of Creativity. Dementia and Neurocognitive Disorders, 15(4), 110-114.

https://dx.doi.org/10.12779\%2Fdnd.2016.15.4.110

Thomton, E. M. (1986). The Freudian fallacy. London: Paladin. 
Zaidel, D. W. (2014). Creativity, brain, and art: biological and neurological considerations. Frontiers in human neuroscience, 8(389), 1-9.

https://doi.org/10.3389/fnhum.2014.00389 